\title{
The Attitude towards Cosmopolitanism in Northern and Southern City Neighborhood (A Case Study in Tehran, Iran)
}

\author{
Hadi Razeghimaleh $^{1}$, Sabah Motevalian ${ }^{2}$ \\ ${ }^{1}$ M.A in Social Science, University of Mazandaran, Babolsar, Iran. \\ ${ }^{2}$ M.A in Social Science, University of Mazandaran, Babolsar, Iran \\ Correspondence: Hadi Razeghimaleh, Department of Social Science, University of Mazandaran, Banolsar, Iran.
}

Received: March 17, 2016

doi:10.11114/ijsss.v4i6.1546
Accepted: March 31, 2016

Available online: April 13, 2016

URL: http://dx.doi.org/10.11114/ijsss.v4i6.1546

\begin{abstract}
This research aims to study the level of a trend to cosmopolitanism in northern and southern urban neighborhood of Tehran. The qualitative method based on a grounded theory is recruited to reach the above mentioned goal. The data in this research are gathered by unstructured interview (in-depth interview) and also based on "Strauss and Corbin approach" the gathered data are analyzed. The research population in this research includes: 18-years -old and above inhabitants of Niawaran and Zafaraniyeh (District 1), and Javadieh and Khazaneh (district 16). The findings in the current research approves that all the 6 interviewed individuals in the northern part of Tehran (Niavaran and Zafaranieh) have a higher level of cosmopolitanism and respect to humanity in comparison to the 5 interviewed individuals living in southern parts(Javadieh and Zafaranieh) of Tehran. Also, the derived codes and the relationships between items clearly show the difference in trend to cosmopolitanism among the participant in this study. Furthermore, in none of the conducted in-depth interview research were approved that two categories of cosmopolitanism and respect to humanity would not be parallel to each other. It means that those who have a high trend to cosmopolitanism have a high respect to humanity too. This is true in lower level of cosmopolitanism.
\end{abstract}

Keywords: Cosmopolitanism, Cultural Values, the Northern Neighborhood of Tehran, the Southern Neighborhood of Tehran, Grounded Theory.

\section{Introduction}

Values are of those topics that have been considered by interdisciplinary fields (philosophy, religion, education, economics, sociology and psychology) and the its importance is obvious, because values direct peoples' behavior and judges and their direction through the evaluation and reflection of the way that people think in a given culture and a specific time (Khalifa, 1378: 23).

The value is some kind of belief that is located in the central form, in an individual's overall belief system and specifies how he/she "should" and "should not" behave, or if you have goals, which have the value of achieving. Values and abstract ideals are positive and negative, and they are not bounded or required to a situation or subject of particular orientation (Rokach, 1976: 124).

Among the studies that have been done in the field of cultural values, comparative study of cultural values between generations has a long history. Most studies (Falk and Falk 2005, Frones 2015, Nevitte and Kanji 2008) that have been done in the field of cultural values are related to the gap between generations. However, this issue can be investigated in the other situations and areas. One of the areas that cultural values can be investigated in that is urban and rural areas. Cosmopolitanism can be understood as the cultural value that in recent years, the interdisciplinary and inter-domain scientific literature has been dealt with it(Gguange 2003, Chen et al 2012, Jeffery and Walks 2013).

Expanding the extra physical boundaries of the countries through different processes or visions has created new streams that Cosmopolitanism is one of them. Since there are many of the scholars' recommendations in order to explain the Cosmopolitanism intellectuals, by studying the scientific literature it can be found that the Cosmopolitanism has a remarkable flow (Miller, 2010; Bayram, 2014; Fine, 2005).

Cosmopolitanism concept has been proposed in social science research about 50 years ago. Cosmopolitanism term or Cosmopolitan is derived from the Greek word of Cosmopolis that means citizen of the world. Being world citizen 
implies important political and normative issues regarding the world order. It is found that identity provides extensive support for political systems. World order is not an exception. Individual is the major unit of the ethical concern in the Cosmopolitan project (Braun and Held, 2010, Pugeh, 1992). Merton considers this concept as some kind of attracting people beyond the local boundaries (Ranjbarian and Gholizdeh Shoghl Abad, 2009: 94).

Cosmopolitan citizenship and a set of Cosmopolitan tendencies such as the positive emotions about migration and low nationalism are intertwined (Bayram, 2014: 2). Typically, Cosmopolitanism is interpreted as a changeable political project, moving towards human rights, democracy and cultural diversity in the era of globalization (Held, 2005).

In many of the scientific literature, the cosmopolitan and nationalism concepts are used together. But at the same time these two concepts are used against each other. But also what is deduced is that the cosmopolitan confirms not only the national identity and nationalism, but also induces the Worldview beyond it. In fact, it can be said that nationalism is a subset of cosmopolitan. Simply, It could be explained that nationalists is only consider the geographical borders of their country as the nation and emphasize national identity, but a cosmopolitan individual does not consider the frontier for the nation and know the whole world as individual homeland. However he does not reject the national identity and holds this view as well.

Another concept that is placed next to the cosmopolitan is the globalization. The globalization process is the increasing expansion of the communication of the various phenomena on a global scale, along with the acquisition of knowledge to the process. So the globalization is not limited to certain areas. It is a process that gradually covers all areas of life, including scientific, political, economic, military, legal and cultural (Ghoraishi, 2002). As it became clear, cosmopolitan is related to how to live in the world and shape the identity for him/herself. Cosmopolitan ideas can be better understood when cosmopolitan people are, in the role of cosmopolitan citizens spread this idea (Fine, 2005: 242).

Therefore, in the light of globalization, the communication level of identity categories expands globally and influence and being influenced of these categories is raised in a global range. For example, if yesterday the factors that lead to identity crisis (identity) were near were we, today with the help of communication technology, remote factors may also cause the identity crisis. If in the past the our identity-maker sources was born out of the immediate environment, now it may be possible that different sources of identity in a long distance has a role in shaping our identity image (Rose, 1380). As it is known, in the light of globalization, national identity can be transferred to a higher level of identity (national identity, global identity, religious identity, etc.). But Cosmopolitan, not only refers to the highest levels of identity (global identity), but also Induces a particular worldview that characterized by the global common values and shared objectives. Moreover, the idea of Cosmopolitan is required widespread civic participation. Also based on the idea of Cosmopolitan, the social, cultural, economic, political, etc. issues has a transnational dimension and cannot be separated from each other and even to solve the problems, the public and global guidelines should also be used.

Due to the wave of the World Values Surveys which was conducted in 57 countries around the world, more than 30 percent of the 65,269 respondents, seriously, identified themselves as the citizens of the world. So the Cosmopolitanism is an important and remarkable phenomenon (Miller, 2010). The Cosmopolitan, is the attitude to yourself as a person, a citizen of the world and this attachment is voluntary and selective (Bayram, 2014: 2).

When we talk about the cosmopolitan, it can be imagined a cultural-social orientation that combines the two dependent dimensions to each other. The first and most basic dimension is what it later called the cosmopolitan Idea, and refers to specific mental state of the cosmopolitan (Hanrez, 1990). Cosmopolitan mindset can be understand as the way of thinking about what Beck(Beck2000, 2006) calls it the imagination of dialogue and thus includes two aspects: on the one hand, the desire to communicate with others and the other tending to identify the orientation and background of the person's cultural identity (Johnson, 2012: 137). Cosmopolitan territorial system includes the experience and the extent of expectations namely internal differences, despite coexistence, the same life style, contrasting certainty in the experience of individuals and communities. It means the world that we require to understand, think about and review its differences and in this way they identify and prove the differences between themselves and others. Cosmopolitan outlook and theoretical sensitivity prepare a space for imagination of dialogue in everyday practice and the related sciences (Beck, 2006: 89). As Dlanty argues, this reflective and critical duality of Cosmopolitan is what distinguishes it from the world. Cosmopolitan ethos emphasizes willingness to change, Self-changing and self-competition (Johnson, 2012: 137). Cosmopolitan is also related to how to live in the world and how to build an identity for your own. Cosmopolitan citizenship can be interpreted as the membership of a cosmopolitan real or imaginary society and as an identity that is called as the trends and cosmopolitan dependencies set. Cosmopolitan idea is important because it is unlikely to understand its required objectives in the absence of cosmopolitan citizens to promote it.

Cosmopolitans warns about proliferation of homogeneous global culture with the argument that attention to the commitment, caring and supervision for the other cultures and dialogue with them is needed (Turner, 2002: 58-57). Cosmopolitanism requires a commitment to global solidarity and world cultural diversity (Turner, 2002). On the other 
hand, Cosmopolitanism in addition to emphasize the transnational culture, does not rule out preserve the national cultural identity and emphasize it as well and notes the importance of preserving cultural diversity. For this reason, it can be stated that, paying attention to the cultural identity of the nations is the key factor of the cosmopolitan theory.

Many political and social theorists have considered cosmopolitan as a radical political project with ambitious Goals(Ruggie 1993, Booth 2001). Reflecting on these ideals allows us to understand citizens' relationship theorizing advantage about the Cosmopolitan. Although it is difficult to identify typical ambition in all situation of the cosmopolitan, there are three themes that are common widely in ideal contemporary formation of cosmopolitan. The first theme is that the principles of justice must be applied in the global context including the principles of the distribution of economic and social products. People with the cosmopolitan tendency claim that citizens have distribution obligations to the similar others namely those who are citizens of the same state (Smith, 2007: 37).

The second theme is that the historical correlation between democracy and nation-states should be discontinued. The cosmopolitans claim that reducing opportunities for meaningful democratic governance at the level of the nation-state, with increased opportunities for arbitrary interference of the new global institutions and actors means that there is the political commitment to form the political community beyond the nation-state (Smith, 2007: 38).

The third theme that is the most innovative and yet the least developed one, is that the cosmopolitan nationalism required the commitment to both the alliance and the cultural diversity of the world (Turner, 2002). The cosmopolitans warns about spreading a homogeneous global culture themselves with the argument that paying attention to the commitment and surveillance for other cultures and dialogue with them is needed (Turner, 2002: 8-57). The requirements of cosmopolitan, global justice, democracy and cultural diversity are very ambitious, certainly need to radical and widespread reforms in the existing regulations. Thus, the requirements of Cosmopolitan have the direct implications for the actions and behaviors of the world population. Citizens also need to be cosmopolitan in their orientation. The idea that there are duties and obligations of cosmopolitan indicates that the concept of cosmopolitan citizenship must be at least partially interpreted as a moral ideal. Cosmopolitan citizenship as a moral ideal requires to possessing special features, an understanding of the regulations or personality traits and what that make us sensitive to the cosmopolitan obligations and duties (Smith, 2007: 38).

In recent years, the cosmopolitanism has become an agenda for research across the humanities and social sciences (Fine, 2005: 242). Recognition of the cosmopolitan level can bring correct understand of identity and its different levels, as well as extending the identity border and worldview in the social, cultural, political, economic dimensions. Therefore, the aim of this qualitative study is investigating the cosmopolitan attitude level in the residents of the north and south of Tehran and qualitative comparing of the two approaches among the groups of residents. Also take a look at the scientific literature available, the existing gap between Persian literatures on the cosmopolitan is clearly evident. Therefore, the study of this issue is necessary to make efforts in order to identify and introduce this concept in the country and also to add literature in the field of the cosmopolitan, in the limited Persian language literatures.

\section{Method}

The purpose of this study is to investigate the cosmopolitan attitude among the residents of the north and south districts of Tehran. The qualitative and research strategy of Grounded Theory was used to achieve the goal. The data for the current study were collected using unstructured interviews (depth interview) and analyzed using Strauss and Corbin's approach.

In qualitative research we cannot determine the sample size before conducting research. For in such research the sampling is performed to theoretical saturation or information satisfaction (explaining and understanding the problem). So that by increasing the sample size, the new information is discovered. Information satisfaction on this study has been obtained with a sample size of 11 persons. The Sample was selected from the residents over 18 years old of the Niavaran and Zaferanieh from the region 1 and Javadieh and Khazane from the region 16 of Tehran.

In this study, the two sampling methods were used. So that the multi-stage cluster sampling method was used to select the district and then purposive sampling method was used for selection of the people. The duration of the interviews ranged between 30 to 50 minutes. In starting the interview, the purpose of the study, how it's done, interview method and freedom of individuals to participate in the study or refuse it was explained for the participants. The principles of confidentiality and acquiring informed consent to interview and record the conversation was observed. The right to withdraw from the study at any time was one of the ethical considerations that were taken into the consideration in the study.

At the beginning of the interview, the general and starting questions were raised and the main questions were raised gradually. Also based on need, the probing questions such as "can you give an example?" Or "Can you explain?" are also used. Finally, questions such as "Do you have any suggestions? "Do you have any questions to ask me?" "Do you 
think that there is a question which has not been raised?" were asked.

Data analysis is performed through the regular process and continuous review and comparing information. So that the three-step process of open coding, axial coding and selective coding is used. In the first stage for open coding, interviews and statements extracted several times and then the codes were assigned them, and finally the similar codes in the main categories (groups and similar) were placed. In the axial coding stage, the relationship of concepts to each other is determined. So that the main classes are connected to the categories and subclasses. In other words, the relationship between the concepts is examined. Finally, in selective coding, the categories are integrated and refined and researcher set them based on a special arrangement between the categories to form a theory.

During the research process the ways were used to ensure the accuracy of the reliability of the study. In qualitative research, four criteria is suggested for the reliability of the study, acceptance, transferability, consistency and Verifiability. In this study, researchers have used long calls with the participants and the research environment, provided information regarding the objectives of the participants in order to gain their trust during the interview, monitored data, recorded voices and analyzed data immediately after the interview and feed backed data for subsequent interviews to increase the acceptance level of data. Verifiability of data was tested through reviewing by participants and observers and using their comments. To search for transferability of study, the results are provided to some of the people living in the neighborhoods of north and south that were out of the sample and they were asked to compare the results with their experiences.

\section{Findings}

Respondents' Demographic characteristics:

Table 1. Demographic characteristics of the respondents

\begin{tabular}{|c|c|c|c|c|c|c|c|c|c|c|c|c|c|}
\hline total & \multicolumn{2}{|c|}{ South } & \multicolumn{2}{|c|}{ North } & \multirow{2}{*}{\multicolumn{2}{|c|}{ variable }} & total & \multicolumn{2}{|c|}{ South } & \multicolumn{2}{|c|}{ North } & \multirow{2}{*}{\multicolumn{2}{|c|}{ variable }} \\
\hline 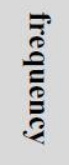 & 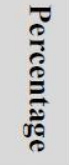 & $\begin{array}{l}\overrightarrow{0} \\
\stackrel{3}{0} \\
\stackrel{0}{3} \\
2\end{array}$ & 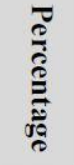 & 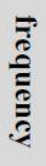 & & & 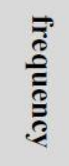 & 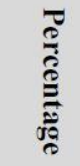 & 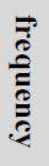 & 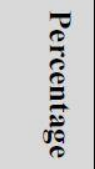 & 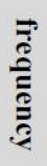 & & \\
\hline 3 & 18.2 & 2 & 9.1 & 1 & $\begin{array}{l}\text { Associate } \\
\text { Degree }\end{array}$ & \multirow{5}{*}{ 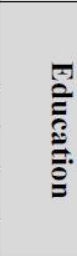 } & 6 & 27.27 & 3 & 27.27 & 3 & male & \multirow{3}{*}{$\mathscr{\circledast}$} \\
\hline 3 & 9.1 & 1 & 18.2 & 2 & BS & & 5 & 18.19 & 2 & 27.27 & 3 & female & \\
\hline 4 & 18.2 & 2 & 18.2 & 2 & master degree & & 11 & \multicolumn{2}{|l|}{5} & \multicolumn{2}{|l|}{6} & total & \\
\hline 1 & 0.0 & 0 & 9.1 & 1 & Ph.D. & & 1 & 0.0 & 0 & 9.1 & 1 & $24-18$ & \multirow{6}{*}{ वैอ } \\
\hline 11 & \multicolumn{2}{|c|}{5} & \multicolumn{2}{|c|}{6} & total & & 3 & 9.1 & 1 & 18.2 & 2 & $31-25$ & \\
\hline 3 & 9.1 & 1 & 18.2 & 2 & single & \multirow{4}{*}{ 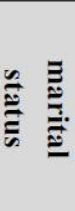 } & 3 & 18.2 & 2 & 9.1 & 1 & $38-32$ & \\
\hline 7 & 36.7 & 4 & 27.7 & 3 & married & & 2 & 9.1 & 1 & 9.1 & 1 & $45-39$ & \\
\hline 1 & 0.0 & 0 & 9.1 & 1 & divorced & & 2 & 9.1 & 1 & 9.1 & 1 & $\begin{array}{l}\text { More } \\
\text { than } 45\end{array}$ & \\
\hline 11 & \multicolumn{2}{|c|}{5} & \multicolumn{2}{|c|}{6} & total & & 11 & \multicolumn{2}{|c|}{5} & \multicolumn{2}{|l|}{6} & total & \\
\hline
\end{tabular}

In this study, 6 of the respondents are male and 5 of them are women. The marital status indicated that 3 of them are single, 7 are married and 1 is single by divorce. Studies show that most of the interviewees have a master's degree and the doctoral degree has the lowest frequency. The age of the respondents indicated that the most frequent age group is 25-31 years and 32-38 years and the lowest frequency is the age group of 18-24 years.

According to the codes that have been extracted from interviews, issues such as respect for humanity, the cosmopolitan and ethnic identity and national identity are discernible.

\section{Respect for humanity:}

After studying the conducted interviews, one of the issues that have been extracted from text and codes is the "respect for humanity" category. Many of interviewed people who have the cosmopolitan orientation has had this characteristic. The issue of respect for humanity exists in the most of the surveyed northern districts of city. Sentences and phrases below shows the code of the issue of the respect for humanity:

- I believe that human beings regardless of ethnicity, language and religion debate are respected only for the human being.

- Human beings, regardless of nationality and religion are respected. 
- It does not matter in what language we're talking, or our skin color is black or white, the important thing is that we all are human.

- $\quad$ It is important to adhere to the basic principles of humanity.

\section{Cosmopolitanism:}

The cosmopolitan is also related to how to live in the world and how to build an identity for ourselves. The cosmopolitan citizenship can be interpreted as membership in a real or supposed society of the cosmopolitan and as an identity that is called trends and dependencies set of the cosmopolitan. In this study, through reviewing interviews, the code belongs to the categories of the cosmopolitan are extracted from the following sentences and phrases.

- $\quad$ I believe that all the world population should know each other as compatriot.

- We are all human. No matter where we are from.

- It does not matter who I am or where you're from. When problems came into existence, belongs to everyone.

- Everyone should extend him/her country border more than what it is now.

\section{Ethnic and national identity}

Ethnic and national identity is among the categories which the code is derived from extracted codes of in-depth interviews. Code of ethnic and national identity issues has been adapted from the following sentences and phrases.

- I do not feel good that we draw a fence around us and say it is my home and the other side does not concern to me.

- Many people know their race superior to any other nation.

- $\quad$ Some people argue ethnic jokes and scoff the other ethnic groups.

Classification of the code extracted from the text 11 of unstructured interview:

Classification of the code extracted from unstructured interviews is provided in the table below.

Table 2. Issues and Themes Drawn From the Statements of Participants

\begin{tabular}{ll}
\hline \multicolumn{1}{c}{ categories } & \multicolumn{1}{c}{ Extracted codes } \\
\hline Respect for humanity & Respect for fellow \\
& Altruism \\
& Avoiding nationalism and racism \\
& Tendency to Cosmopolitan \\
& Avoiding life world prejudice \\
& Avoiding racism \\
& Avoiding nationalism \\
& Holism \\
& Opposition to nationalism and racism \\
& Expansion the borders of the homeland \\
& Life world identity \\
& Ethnicity \\
& Ethnicity and racism \\
The intensity of ethnic identity & Intolerance to ethnic identity \\
\hline
\end{tabular}

Two of the main issues that have been identified by researchers as follows:

- Tendency to the cosmopolitan

- $\quad$ Respect for humanity

To examine the relationship and also developing the relationship between the two concepts, we have used the following mini-framework. This mini-framework indicates the points that two concepts of cosmopolitanism and respect for humanity meet each other. 


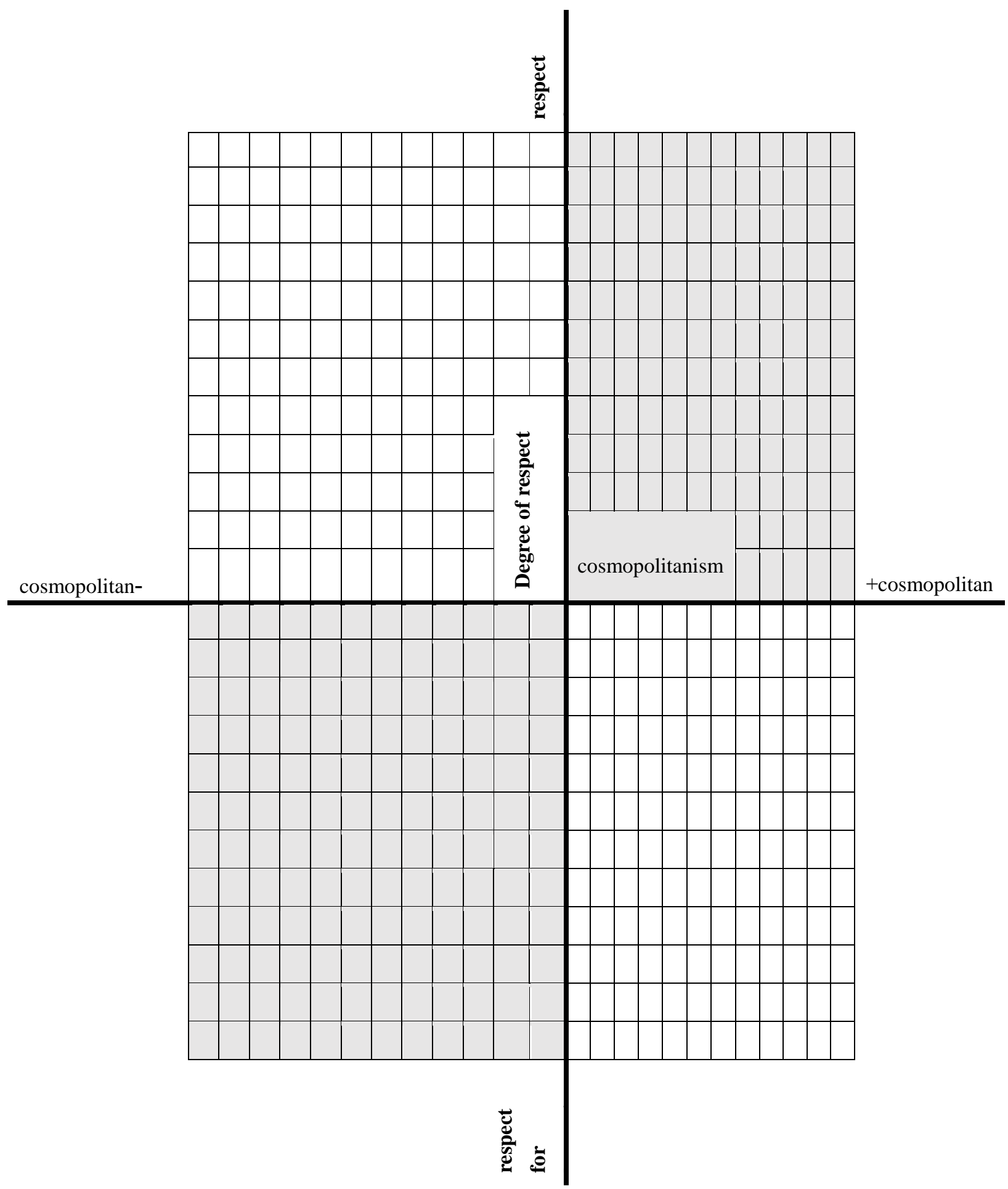

Figure 1. The Intersection mini-framework between the two concepts of cosmopolitan and respect for humanity

In the figure above, each of the intersections shows the status of respect for humanity and the cosmopolitanism. In the present study, all the 11 interviewees were placed in the specified sections of the chart. The difference is that all 6 interviewees from the residents of north of Tehran (Niavaran and Zaferaniyeh) were placed in the positive section of the cosmopolitan and respect for humanity chart and 5 respondents from the southern Tehran (Javadieh and Khazaneh) were placed in the negative section of the cosmopolitan and respect for humanity chart. In other words, it can be stated that the subjects who lived in the neighborhoods of northern Tehran, were more inclined to the cosmopolitan and the 
respect for humanity than the people living in the south of the city. In addition, the extracted codes and the relationships between categories clearly reflect the difference in the cosmopolitan tendency level among subjects in the north and south of Tehran. The cosmopolitanism and respect for humanity have also the same direction. This means that people who tend to be cosmopolitan have also high amount of respect for humanity. This is also true about the low tendency for the cosmopolitan.

The researchers have compared the models derived from texts based on personal characteristics based on the identification and development of the relationship between categories. Therefore, after reviewing the literature, differences in attitudes to the cosmopolitan as well as the respect for humanity were significant in terms of the in gender, education and age.

Based on the extracted codes from the texts of the in-depth interviews and obtained categories the tendency to the cosmopolitan and respect for the humanity in surveyed men were more than the women. In addition, people with the postgraduate education had the more tendencies to the cosmopolitanism and the respect for the humanity relative to the other degrees. The difference is also evident in the age variable. This means that people who are older have shown higher tendency to the cosmopolitanism and respect for humanity than the people in the younger groups.

\section{Results}

This research aims to study the level of a trend to cosmopolitanism in northern and southern urban neighborhood of Tehran. The qualitative method based on a grounded theory is recruited to reach the above mentioned goal. The data in this research are gathered by unstructured interview (in-depth interview) and also based on "Strauss and Corbin approach" the gathered data are analyzed. The research population in this research includes: 18-years -old and above inhabitants of Niawaran and Zafaraniyeh (District 1), and Javadieh and Khazaneh (district 16). The findings in the current research approves that all the 6 interviewed individuals in the northern part of Tehran (Niavaran and Zafaranieh) have a higher level of cosmopolitanism and respect to humanity in comparison to the 5 interviewed individuals living in southern parts (Javadieh and Zafaranieh) of Tehran. Also, the derived codes and the relationships between items clearly show the difference in trend to cosmopolitanism among the participant in this study. Furthermore, in none of the conducted in-depth interview research were approved that two categories of cosmopolitanism and respect to humanity wouldn't be parallel to each other. It means that those who have a high trend to cosmopolitanism have a high respect to humanity too. This is true in lower level of cosmopolitanism.

In this research a trend to cosmopolitanism and the level of respect to humanity according to individual characteristics of participants is studied. The findings approve, in terms of gender, a trend to cosmopolitanism and respects to humanity are higher, in comparison to females, among the male individuals. Also, those who hold higher education and the older individuals have a higher level of cosmopolitanism and respect to humanity, in comparison to those with lower level of academic education and the Youngers.

\section{Reference}

Abdollatif, M. (1999). the psychological Study of evolution in Values/ Translated by: Hossein S, Mashhad, Astan Ghods-e Razawi Pub.

Bayram. A. B. (2014) what drives modern Diogenes? Individual values and cosmopolitan allegiance, European Journal of International Relations, 1-29. http://dx.doi.org/10.1177/1354066114541879

Beck, U. (2000). the Cosmopolitan Perspective. On the Sociology of the Second age of Modernity. British Journal of Sociology, 51, 79-106.

Beck. U. (2006) the Cosmopolitan Vision. Cambridge: Polity Press.

Beck. U. (2006). The Cosmopolitan Vision. Cambridge, UK :Polity Press.

Booth, K. (2001). Ten Flaw of Just Wars. In The Kosovo Tragedy: The Human Rights Dimensions, edited by K.Booth. London: Frank Cass, 314-324.

Brown. G. W., \& Held. D. (2010a). The Cosmopolitan Reader. Malden, MA: Polity Press.

Chen, X. Y., Wang, L., \& Liu, J. S. (2012) Adolescent Cultural Values and Adjustment in the Changing Chinese Society, In Trommsdorff. Gisela and Chen, Xinying (Eds) Values, Religion, and Culture in Adolescent Development, Cambridge, 235-252.

Falk, G., \& Falk, U. (2005). Youth Culture and Generational Gap, Algora Publishing, New York.

Fine. R. (2005) Cosmopolitanism: A Social Science Research Agenda, in G. Delanty (ed.), Handbook of Contemporary European Social Theory. London: Routledge.

Frones, I. (2015) The Autonomous Child: Theorizing Socialization, Springer 
Ghoraishi, F. (2002) Globalization and the Changes in our imagination toward self/ Motaleeate Meli Quartely, 3(11), 37-58.

Golmohammadi, A. (2001). Modernity, Globalization, and Identity: the cultural determinism of contemporary world/ a PhD thesis in Political Science, Supervised by: Ahmadi H, Department of Law and Political Science, Tehran University.

Hannerz. U. (1990). Cosmopolitans and locals in a world culture, Theory, Culture \& Society, 7(2), $237-251$. http://dx.doi.org/10.1177/026327690007002014

Jansson, A. (2012) A second birth? Cosmopolitan media ethnography and Bourdieu's reflexive sociology, International Journal of Cultural Studies, 16(2), 135-150. http://dx.doi.org/10.1177/1367877912452483

Lei, G. (2003). Rural Taste, Urban Fashions: The Cultural Politics of Rural/Urban Differences in Contemporary China, positions: east asia cultures critique, 11, 613-646.

Miller. D. (2010). Cosmopolitanism. In: Brown GW and Held D (eds) The Cosmopolitan Reader. Malden, MA: Polity Press, 377-393.

Nevitte, N., \& Kanji, M. (2008) Cleavages, Value Gap, and Regime Support. In Pettersson. Thorleif and Esmer. Ylmaz (Eds) Changing Values, Persisting Cultures: Case Studies in Value Change, Brill Publishing.

Pogge. T. W. (1992) Cosmopolitanism and sovereignty, Ethics 103(1), 48-75. http://dx.doi.org/10.1086/293470.

Ranjbarian.B, Gholizadeh. R(2009) Ethnicity in Consumption and its Relationship with Patriotism and the Cosmopolitan Tendencies among the Students in Esfahan University, Business Management Quarterly Journal, 87-106 (in Farsi)

Rokeach, M. (1976). Beliefs, attitude and values: a theory of organization and change, sanfrancisco.

Ruggie, J. G. (1993). Territoriality and Beyond: Problematizing Modernity in International Relations. International Organization, 47(1), 139-174. http://dx.doi.org/10.1017/S0020818300004732

Seller, M. J., \& Walks, A. (2013). The Metropolitanisation of Politics. In Seller, M Jeffery, Kubler. Daniel, Walter-Rogg. Melanie, and Walks. Alan(Eds) The Political Ecology of the Metropolis Metropolitan Sources of Electoral Behaviour in Eleven Countries, ECPR Press, 3-35.

Smith. W (2007). Cosmopolitan Citizenship Virtue, Irony and Worldliness, European Journal of Social Theory 10(1), 37-52. http://dx.doi.org/10.1177/1368431006068755

Turner. B. S. (2002) Cosmopolitan Virtue: Globalization and Patriotism, Theory, Culture \&Society, 19(1), 45-63. http://dx.doi.org/10.1177/026327640201900102

\section{(cc) $\mathrm{EY}$}

This work is licensed under a Creative Commons Attribution 3.0 License. 